\title{
Auditory Training in an Elderly Hearing Aid User Using Environmental Sounds, Stories and Questions: A Case Report
}

\author{
Seeon Kim, Kyoungwon Lee \\ Department of Audiology and Speech-Language Pathology, Hallym University of Graduate Studies, Seoul, Korea
}

보청기 착용 노인의 환경음과 이야기 답변을 이용한 청능훈련: 사례 보고

김 시 온·이 경 원

한림국제대학원대학교 청각언어치료학과

\begin{abstract}
We have reported one case of improvement in word recognition score (WRS) and sentence recognition score (SRS) in an elderly hearing aid user who had difficulty in communicating with others even after having a hearing aid fitted. Six weeks of training was conducted using environmental sounds, stories, and questions. Auditory training was conducted twice a week in hearing aid fitting room and total training time in each session was 40 minutes, including checking hearing aids, pre-training counseling, auditory training, and post-training counseling. After three weeks of auditory training, the WRSs of the left and right ear with headphone were changed $28 \%$ to $48 \%$ and $28 \%$ to $40 \%$, respectively. After six weeks of training, SRSs in the acoustic room were improved $47.5 \%$ to $77.5 \%$ with hearing aids on both sides. And the Korean version of profile of hearing aid benefit scores after six weeks of training were $15.3 \%$ for easy communication, $62.3 \%$ for background noise, 34.3\% for aversiveness, and 50.0\% for localization except reverberation situation. This study showed that an elderly hearing aid user has improved communication skills, despite the short period of training. In addition, various training tools and methods are required to ensure that the subject does not lose interest in auditory training, and if the duration and place for the auditory training are limited, a training application on a personal computer or smartphone may facilitate auditory training.
\end{abstract}

Key Words: Auditory training, Environmental sound, Story and question, Neuroplasticity, Hearing loss.

Received: June 12, 2018 / Revised: July 6, 2018 / Accepted: July 9, 2018

Correspondence: Kyoungwon Lee, Department of Audiology and Speech-Language Pathology, Hallym University of Graduate Studies, 427 Yeoksam-ro, Gangnam-gu, Seoul 06197, Korea

Tel: +82-2-2051-4951 / Fax: +82-2-3453-6618 / E-mail: leekw@hallym.ac.kr

\section{INTRODUCTION}

대부분의 난청인들은 보청기 등의 증폭기기를 착용한 후에 도 의사소통에 어려움이 있어서 보청기의 착용을 거부하거나 적응에 실패하는 비율이 높게 나타나고 있다(Koo et al., 2006). 따라서 난청인이 착용한 보청기 등의 청각기기를 최적으로 조 절하였음에도 불구하고 일상생활에서의 대화능력이 저하된다 면 청능훈련(auditory training)을 시도할 필요가 있다(Humes et al., 2014). 청능훈련은 집중적인 듣기훈련을 통해 청각피질을 변화시키는 신경가소성(neuroplasticity)으로 인해 난청인의 의 사소통능력을 향상시킬 수 있는 것으로 알려져 있다(Brouns et al., 2011; Sweetow \& Sabes, 2006, 2010). 청능훈련은 특히 보
청기, 인공와우 등 청각기기를 착용했을 때 착용한 기기의 효과 를 극대화할 수 있는 이점이 있다(Morais et al., 2015).

국내외의 다양한 연구에서는 청능훈련을 시행했을 때 단어 인지도, 문장인지도 등 어음의 인지능력이 향상되었음을 보고 하였다. 외국의 경우 Stecker et al.(2006)은 잡음하에서 음절을 인지하는 훈련을 집 또는 별도로 마련한 훈련실에서 8 주간 실 시했을 때 감각신경성 난청인의 무의미음절(nonsense syllable) 인지도가 개선되었으며, Burk \& Humes(2008)는 난청 노인이 소음하에서 단어를 이용한 청능훈련을 12 주간 실시했을 때 단 어인지도가 향상되었음을 보고하였다. 또한 Humes et al.(2014) 은 단어를 기반으로 청능훈련을 실시했을 때 유의미한 단어인 지도의 개선이 나타났다고 보고하였다. 그리고 국내 연구에서 
환경음(Kim \& Lee, 2017), 단음절어(Kim \& Lee, 2010), 시간 압축 문장(Jo et al., 2013), 소음하 문장(Yeo et al., 2014) 등을 이용하여 6주 이상의 청능훈련을 실시했을 때 조용한 곳 및 소 음하에서 단어 또는 문장인지도가 개선되었음을 보고하였다. 대 부분의 연구에서 의사소통능력의 개선에 필요한 주당 횟수는 2 회 이상, 총 훈련 기간은 5 주에서 15 주 정도이며, 청능훈련이 끝 난 후에도 어음인지의 효과는 지속된다고 보고하였다(Humes et al., 2014).

청능훈련에는 환경음, 음악, 어음 등 다양한 음원 도구가 사 용될 수 있는데 한국의 경우 신호음을 처리하는 복합적인 과정 이 어음을 인지하는 방법과 공통적인 요인을 포함하고 있는 (Shafiro et al., 2011) 환경음(Ahn \& Lee, 2016)을 비롯하여 가 로세로 단어퀴즈(Baek \& Lee, 2016), 이야기와 질문(Lim \& Bahng, 2016), 문장(Chang \& Lee, 2016) 등 어음을 이용한 다 양한 청능훈련 도구를 개발하였다. 또한 그림판을 사용한 아동 용 청능훈련 도구를 개발하였다(Lee et al, 2017).

본 사례에서는 의사소통의 어려움을 개선하기 위해 보청기를 교체하였으나 효과를 보지 못한 노인에 대하여 환경음과 이야 기 답변 기반의 청능훈련 후에 헤드폰 착용 시의 단어인지도 및 방음실에서의 문장인지도가 개선된 사례가 있어서 이를 보고하 고자 하였다.

\section{CASE REPORT}

\section{대상자}

\section{기본 정보 및 방문 목적}

대상자는 방문 당시 66세로 2009년경에 난청이 있음을 인지 하였으며, 12 채널의 고막형 보청기를 양측에 착용하고 있었다. 난청 관련 가족력은 없고, 갑상선 질환을 가지고 있으며, 2017년 초 백내장 수술을 받은 바 있다고 하였다. 문구류 제조업을 운
영하고 있으나 난청으로 인해 타인과의 대화 시간이 적다고 하 였다. 대상자는 $1.0 \mathrm{~mm}$ 의 환기구를 설치한 고막형의 6 채널 디 지털 보청기를 착용하고 있었으며, 방문 목적은 다양한 환경에 서의 의사소통 및 TV 시청에 어려움이 있어서 이를 해결하고 자 하였다.

\section{기도 청력역치레벨}

Table 1에서 대상자의 2010년과 2017년 기도 청력역치레벨을 비교해 보면 좌측의 경우는 $250 \mathrm{~Hz}$ 와 $8,000 \mathrm{~Hz}$ 에서 $15 \mathrm{~dB}$ 이 상승하였을 뿐 전체적으로 큰 변화는 나타나지 않았다. 그러나 우측의 경우는 $250 \mathrm{~Hz}, 500 \mathrm{~Hz}, 2,000 \mathrm{~Hz}$ 의 청력역치레벨이 25 30 dB 정도 상승하였다.

\section{어음청각검사}

Table 2에서 대상자의 2010년과 2017년 TDH-50 (Telephonics, New York, NY, USA) 헤드폰을 통한 단어인지도를 비교 해 보면 좌측은 $34 \%$ 에서 $28 \%$ 로 변화하여 비슷하게 나타났지 만, 우측은 $72 \%$ 에서 $28 \%$ 로 저하된 것으로 나타났다. 그리고 Table 3의 음장에서 양측에 보청기를 착용한 상태에서의 문장 인지도는 2010년의 56\%에서 2014년의 $40 \%$ 로 저하되었다. 그리 고 2015년과 2017년, 좌우측을 각각 측정한 문장인지도는 28 36\%로 비슷하게 나타났다.

Table 3. Aided sentence recognition scores at $50 \mathrm{~dB} \mathrm{HL}$ in the sound field

\begin{tabular}{clc}
\hline Year & Site & \% of correct \\
\hline 2010 & Both & 56 \\
2014 & Both & 40 \\
2015 & Right & 36 \\
& Left & 36 \\
2017 & Right & 36 \\
& Left & 28 \\
\hline
\end{tabular}

Table 1. Air conduction hearing threshold level $(\mathrm{dB} H \mathrm{HL})$ of the subject in octave band frequencies $(\mathrm{kHz})$

\begin{tabular}{|c|c|c|c|c|c|c|c|c|c|c|c|c|}
\hline \multirow{2}{*}{ Date } & \multicolumn{6}{|c|}{ Right } & \multicolumn{6}{|c|}{ Left } \\
\hline & 0.25 & 0.5 & 1 & 2 & 4 & 8 & 0.25 & 0.5 & 1 & 2 & 4 & 8 \\
\hline 2010.12. 01 & 45 & 30 & 20 & 35 & 65 & 80 & 70 & 55 & 60 & 60 & 65 & 75 \\
\hline 2014. 04. 11 & 75 & 65 & 50 & 50 & 80 & 100 & 60 & 65 & 70 & 55 & 70 & 85 \\
\hline 2017.02. 02 & 75 & 70 & 45 & 60 & 70 & 90 & 85 & 80 & 65 & 60 & 65 & 85 \\
\hline
\end{tabular}

Table 2. Unaided word recognition scores of subject with TDH-50 (Telephonics) headphone

\begin{tabular}{cccccc}
\hline \multirow{2}{*}{ Date } & \multicolumn{3}{c}{ Right } & & \multicolumn{2}{c}{ Left } \\
\cline { 2 - 3 } \cline { 5 - 6 } & \% of correct & Presentation level (dB HL) & & \% of correct & Presentation level (dB HL) \\
\hline 2010.12 .01 & 72 & 60 & 34 & 80 \\
2014.04 .11 & 18 & 65 & 32 & 90 \\
2017.02 .02 & 28 & 80 & 28 & 95 \\
\hline
\end{tabular}




\section{$\mathrm{K}-\mathrm{PHAB}$ 평가}

방문 당시 대상자의 의사소통능력은 Kim et al.(2016)이 the abbreviated profile of hearing aid benefit (APHAB) (Cox \& Alexander, 1995)를 수정하여 한국어로 개발한 Korean version of profile of hearing aid benefit (K-PHAB) 설문지를 이용하 여 평가하였는데, 방문 당시의 범주(category)별 점수는 easy communication (EC)은 21.8\%, background noise (BN)는 87.0\%, reverberation $(\mathrm{RV})$ 은 $84.0 \%$, aversiveness $(\mathrm{AV})$ 는 $65.5 \%$, localization (LC)은 $75.0 \%$ 로 나타났다.

\section{보청기의 선택}

방문 당시 착용한 보청기의 $\mathrm{K}-\mathrm{PHAB}$ 결과를 토대로 잡음 및 울리는 공간에서 어음인지능력을 개선하기 위해 잡음감소 (noise reduction) 기능이 있는 12 채널의 보청기를 선택하였다. 보청기의 형태는 고막형으로 직경 $1.0 \mathrm{~mm}$ 의 환기구 그리고 손 잡이(removal handle)를 설치하였다.

\section{보청기의 조절 및 확인}

보청기의 조절은 NAL-NL2 (National Acoustic Laboratories, version 2, Chatswood, New South Wales, Australia)를 기 준으로 대상자가 느끼는 음량 및 음질을 토대로 조절하였다. 실 이측정(real-ear measurement)에서 보통 크기의 어음을 제시 했을 때 어음스펙트럼이 NAL-NL2의 목표 출력음압에 근접 함을 확인하였다. 2017년 05월 16일에 최종적으로 조절한 보청 기를 FONIX 8000 (Frye, Beaverton, OR, USA)의 ANSI S3.42 (2003)로 분석했을 때 최대이득은 $20 \mathrm{~dB}$ 내외로 나타났다 (Figure 1). 그림에서 우측의 보청기(Figure 1A)는 음향피드백의 영향으로 음향피드백제어(anti-feedback reduction system) 기 능을 켬으로 인해 고주파수 대역의 이득이 낮게 나타났다.

\section{청능훈련}

\section{청능훈련 도구}

Kim \& Lee(2017), Yeo et al.(2014) 등은 환경음 또는 문장 을 이용한 훈련이 난청인의 단어 또는 문장의 인지에 효과가 있었다고 하였다. 이에 본 사례에서는 난청인의 훈련에 대한 흥 미를 유발하기 위하여 Ahn \& Lee(2016)가 개발한 환경음 및 $\operatorname{Lim} \&$ Bahng(2016)이 개발한 이야기 답변 도구를 혼합하여 사용하였다.

\section{청능훈련 계획 및 요약}

청능훈련 기간은 Humes et al.(2014)의 연구를 기초로 하여
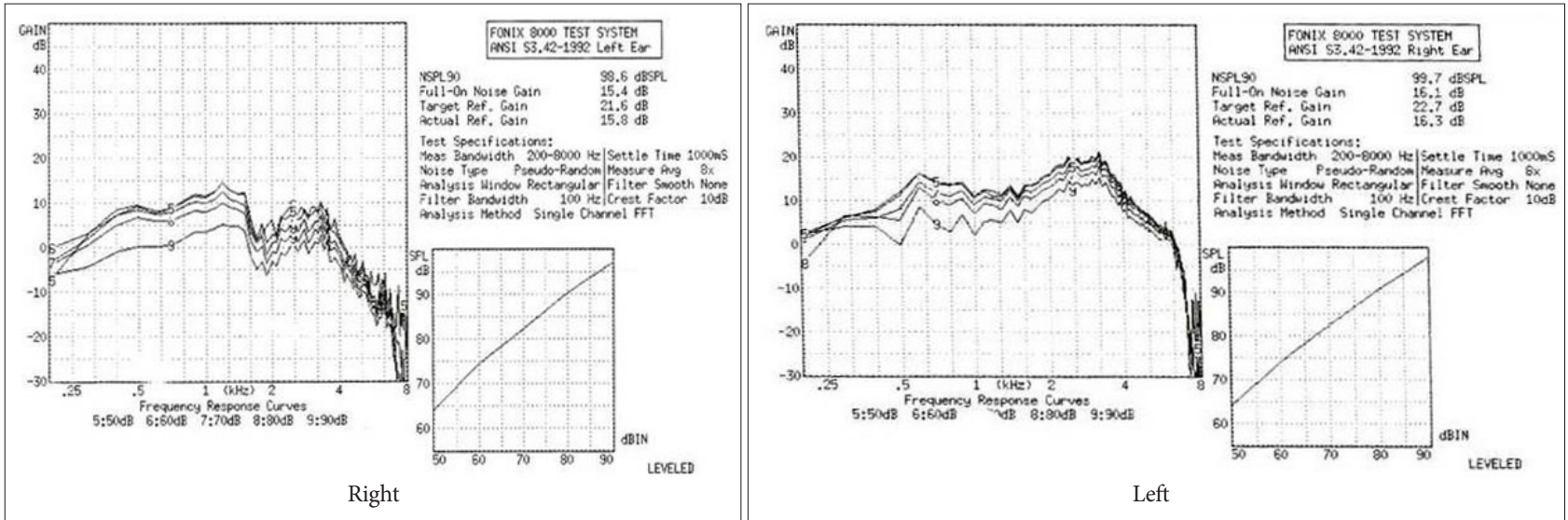

Figure 1. Electroacoustic characteristics of the subject's new hearing aid according to ANSI S3.42 (2003).

Table 4. Organization of each auditory training session

\begin{tabular}{|c|c|c|}
\hline Items & Time required (minute) & Details \\
\hline \multirow[t]{2}{*}{ Checking hearing aid } & 5 & Hearing aid analysis \\
\hline & & Hearing aid repair \\
\hline \multirow[t]{2}{*}{ Counseling before training } & 5 & $\begin{array}{l}\text { Checking the listening environments (conversation with others in various situation, } \\
\text { watching TV, using telephone, and etc.) }\end{array}$ \\
\hline & & Additional considerations \\
\hline Auditory training & 25 & Auditory training \\
\hline \multirow[t]{2}{*}{ Counseling after training } & 5 & Feedback for auditory training \\
\hline & & Orientation for listening strategies at various situations \\
\hline
\end{tabular}


Table 5. Unaided word WRSs with a headphone and aided SRSs in the sound field

\begin{tabular}{|c|c|c|c|c|c|}
\hline \multirow[b]{2}{*}{ Period } & \multirow[b]{2}{*}{ Site } & \multicolumn{2}{|c|}{ Unaided WRS (\%) } & \multicolumn{2}{|c|}{ Aided SRS (\%) in quiet } \\
\hline & & With headphone & $\begin{array}{c}\text { Presentation level } \\
\text { (dB HL) }\end{array}$ & In sound field & $\begin{array}{c}\text { Presentation level } \\
\text { (dB HL) }\end{array}$ \\
\hline \multirow[t]{2}{*}{ 2017. 02.02 (pre-training) } & Right & 28 & 80 & 37.5 & \multirow{8}{*}{50} \\
\hline & Left & 28 & 95 & 27.5 & \\
\hline \multirow[t]{3}{*}{ 2017. 06.03 (3 weeks of training) } & Right & 48 & 85 & - & \\
\hline & Left & 40 & 90 & - & \\
\hline & Both & - & - & 47.5 & \\
\hline \multirow[t]{3}{*}{ 2017. 06. 21 (6 weeks of training) } & Right & 48 & 85 & - & \\
\hline & Left & 36 & 85 & - & \\
\hline & Both & - & - & 77.5 & \\
\hline
\end{tabular}

WRS: word recognition score, SRS: sentence recognition score

총 16 주의 훈련을 계획하였으나 대상자 개인의 사정으로 훈련 을 지속할 수 없어서 6주 후에 청능훈련을 종료하였다. 본 사례 에서 실시한 6주간의 청능훈련 도구 및 환경 그리고 대상자의 반응 및 보고사항은 Appendix에 정리하였다.

\section{청능훈련의 구성}

회당 청능훈련의 구성과 이에 소요되는 시간은 착용한 보청 기의 확인 5 분, 훈련 전 상담 5 분, 청능훈련 25 분, 훈련 후 상담 5 분으로 총 시간은 40 분이었다. 훈련의 구성에 따른 주요 내용 은 Table 4에 나타내었다.

\section{훈련효과의 평가}

훈련효과의 평가는 훈련 실시 3주 후 및 6주 직후에 실시하 였다. 평가 내용은 헤드폰 착용 시 단어인지도, 방음실에서의 문장인지도 및 $\mathrm{K}-\mathrm{PHAB}$ 의 변화를 살펴보았다.

\section{단어인지도 및 문장인지도의 변화}

헤드폰 착용 시 훈련 전, 훈련 3주 후, 그리고 6주 후의 단어 인지도는 우측이 $28 \%, 48 \%$, 그리고 $48 \%$ 로 각각 나타났으며, 좌측은 $28 \%, 40 \%$, 그리고 $36 \%$ 로 각각 나타났다. 단어인지도에 있어서 좌우측 모두 훈련 3주 후에 훈련 전과 비교했을 때 가장 큰 차이를 나타냈다. 그리고 방음실에서의 문장인지도는 훈련 3 주 후의 $47.5 \%$ 에서 6 주 후에는 $77.5 \%$ 로 개선된 것으로 나타 났다(Table 5).

\section{$\mathrm{K}-\mathrm{PHAB}$ 의 변화}

Figure 2에서 6주 후의 K-PHAB은 EC는 $15.3 \%$, BN은 62.3\%, $\mathrm{RV}$ 는 $81.0 \%, \mathrm{AV}$ 는 $34.3 \%, \mathrm{LC}$ 는 $50.0 \%$ 로 나타나 대부분의 상 황에서 의사소통능력의 개선이 있었음을 확인하였다. 그러나 소리가 울리는 공간(RV)에서의 의사소통능력은 훈련 전과 비 교했을 때 차이가 없는 것으로 나타났다.

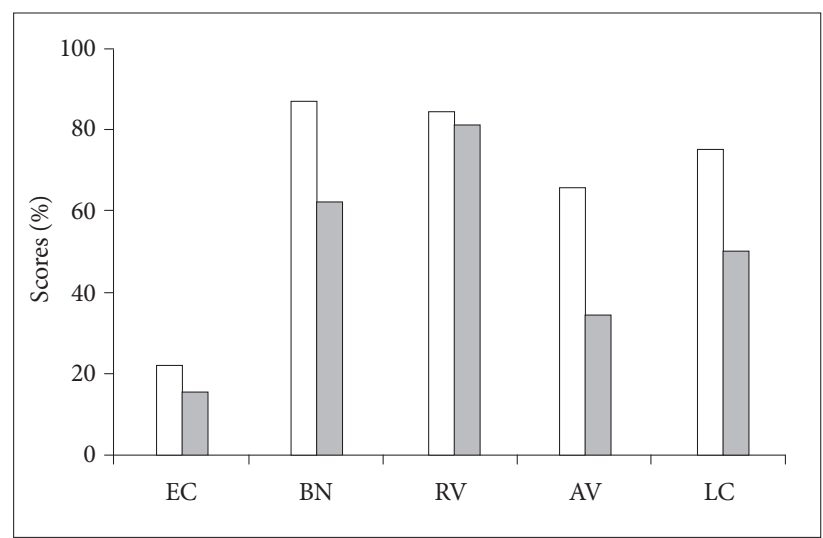

Figure 2. Korean version of profile of hearing aid benefit scores of pre- and post-training. White bar: pre-training, black bar: post training. EC: easy communication, BN: background noise, RV: reverberation, $\mathrm{AV}$ : aversiveness, LC: localization.

\section{DISCUSSIONS}

본 사례에서는 6주간 청능훈련을 실시한 후 보청기를 착용 한 감각신경성난청 노인의 단어 및 문장 인지도를 개선한 사례 를 보고하였다.

본 사례에서 대상자의 청능훈련 도구로 환경음과 이야기 답 변의 어음을 사용하였다. 환경음은 다양한 주파수 대역의 정보 를 포함하고 있으며, 신호음을 처리하는 복합적인 과정이 어음 을 인지하는 방법과 공통적인 요인을 포함하고 있다고 하였다 (Shafiro et al., 2011). 본 연구 대상자의 경우 환경음을 이용한 청능훈련을 마친 3주 후 헤드폰 착용 시 우측의 단어인지도는 $28 \%$ 에서 $48 \%$, 좌측이 $28 \%$ 에서 $40 \%$ 로 증가하여 Shafiro et al. (2011)의 연구 결과와 일치성을 나타냈다. 하지만 방음실에서 양측에 보청기를 착용한 후의 문장인지도는 크게 증가하지 않 은 것으로 나타났다. 또한 이야기 답변 기반의 청능훈련 3주 후 헤드폰 착용 시의 단어인지도는 크게 변화하지 않았으나 방음 실에서 양측 보청기 착용 후 문장인지도는 3주 차의 $47.55 \%$ 에 
서 6주 차의 $77.5 \%$ 로 크게 증가한 것으로 나타났다. 본 사례의 결과를 Jo et al.(2013), Yeo et al.(2014)의 연구와 비교했을 때 본 연구 대상자의 문장인지도가 큰 폭으로 증가하여 차이를 나 타냈다. 그러나 Humes et al.(2014)의 연구에서는 청능훈련 후 소음하에서의 문장인지도가 $30 \%$ 에서 $40 \%$ 정도가 상승하여 본 사례와 일치성을 나타냈다.

본 사례에서 청능훈련 기간은 대상자의 사정으로 주 2회씩 6 주로 Jo et al.(2013), Kim \& Lee(2010), Kim \& Lee(2017), Yeo et al.(2014) 등 다른 연구의 8주에 비해서 짧은 편이었다. 그러나 Humes et al.(2014)이 청능훈련의 효과를 극대화하기 위해서는 5 주에서 15 주의 기간이 필요하다고 하였듯이 6 주간의 청능훈 련 기간 또한 난청인의 청능훈련 기간으로 가능할 것으로 보인다.

청능훈련은 Laplante-Lévesque et al.(2010), Sweetow \& Sabes(2010)가 지적하였듯이 대상자가 흥미를 가지고 적극적이 며 자발적으로 참여할 수 있도록 하는 것이 중요하다. 따라서 청능훈련에 사용하는 도구에 있어서도 환경음, 음악을 비롯하 여 단음절어, 낱말, 이야기 또는 문장 등 다양한 음원을 사용 하는 것이 효과적이라 하겠다.

다양한 선행연구와 본 사례를 통하여 청능훈련이 청각기기 를 착용한 난청인의 어음인지 등 의사소통능력의 개선에 도움 을 줄 수 있음을 확인할 수 있었다. 청능훈련에 영향을 주는 요 소는 훈련도구, 회당 훈련 구성, 주당 훈련 시간 및 총 훈련 기 간이 중요하다. 그러나 실제 청능재활 현장에서는 청능훈련 대 상자의 여러 가지 상황으로 인해 훈련에 충실히 임하기 어려울 수 있을 것으로 보인다. 따라서 시간과 장소에 구애를 받지 않 고 훈련을 실시할 수 있는 청능훈련 웹 또는 앱의 개발이 난청 인의 청능훈련에 도움을 줄 수 있을 것으로 생각한다.

중심 단어 : 청능훈련·환경음·이야기 답변·신경가소성·난청.

\section{Ethical Statement}

This study was approved by the Institutional Review Board of Hallym University of Graduate Studies (IRB \# HUGSAUD 712564).

\section{Acknowledgments}

The authors thank to the participant.

\section{Declaration of Conflicting Interests}

There are no conflict interests.

\section{Funding}

N/A

\section{REFERENCES}

Ahn, P. \& Lee, K. (2016). Development of environmental sounds for auditory training. Audiology and Speech Research, 12(2), 82-88.
American National Standards Institute. (2003). Testing Hearing Aids with a Broadband Noise Signal, ANSI S3.42. New York, NY: Acoustical Society of America.

Baek, S. S. \& Lee, J. H. (2016). Development of crossword puzzles for auditory training. Audiology and Speech Research, 12(2), 103-108.

Brouns, K., El Refaie, A., \& Pryce, H. (2011). Auditory training and adult rehabilitation: A critical review of the evidence. Global Journal of Health Science, 3(1), 49-63.

Burk, M. H. \& Humes, L. E. (2008). Effects of long-term training on aided speech-recognition performance in noise in older adults. Journal of Speech, Language, and Hearing Research, 51(3), 759-771.

Chang, S. \& Lee, J. (2016). Development of auditory training tool for adults using sentences. Audiology and Speech Research, 12(2), 89-96.

Cox, R. M. \& Alexander, G. C. (1995). The abbreviated profile of hearing aid benefit. Ear and Hearing, 16(2), 176-186.

Humes, L. E., Kinney, D. L., Brown, S. E., Kiener, A. L., \& Quigley, T. M. (2014). The effects of dosage and duration of auditory training for older adults with hearing impairment. The Journal of the Acoustical Society of America, 136(3), EL224.

Jo, Y. Y., Bahng, J., \& Lee, J. H. (2013). Case study of auditory training for an elderly hearing aid user. Audiology and Speech Research, 9(2), 190194.

Kim, H. G. \& Lee, K. W. (2010). Effects of word recognition score as a function of auditory training terms for elderly hearing impaired with hearing aid. Audiology and Speech Research, 6(2), 159-163.

Kim, J. \& Lee, K. (2017). Effects on word and sentence recognition by auditory training using environmental sound for elderly hearing impaired. Audiology and Speech Research, 13(2), 115-122.

Kim, T., Sim, S., \& Lee, K. (2016). Development of Korean version of profile of hearing aid benefit. Audiology and Speech Research, 12(4), 209-220.

Koo, S. M., Kim, J. S., \& Lim, D. H. (2006). A summary of the census for the disabled in Korea-focusing on the hearing impaired. Audiology and Speech Research, 2(1), 52-57.

Laplante-Lévesque, A., Hickson, L., \& Worrall, L. (2010). Rehabilitation of older adults with hearing impairment: A critical review. Journal of Aging and Health, 22(2), 143-153.

Lee, J. I., Bahng, J., \& Lee, J. H. (2017). Development and verification of auditory training tool for children. Audiology and Speech Research, 13(2), 123-132.

Lim, E. H. \& Bahng, J. (2016). Preliminary study for development of auditory training tool using story and question. Audiology and Speech Research, 12(2), 109-114.

Morais, A. A., Rocha-Muniz, C. N., \& Schochat, E. (2015). Efficacy of auditory training in elderly subjects. Frontiers in Aging Neuroscience, 7, 78.

Shafiro, V., Gygi, B., Cheng, M. Y., Vachhani, J., \& Mulvey, M. (2011). Perception of environmental sounds by experienced cochlear implant patients. Ear and Hearing, 32(4), 511-523.

Stecker, G. C., Bowman, G. A., Yund, E. W., Herron, T. J., Roup, C. M., \& Woods, D. L. (2006). Perceptual training improves syllable identification in new and experienced hearing aid users. Journal of Rehabilitation Research and Development, 43(4), 537-552.

Sweetow, R. W. \& Sabes, J. H. (2006). The need for and development of an adaptive Listening and Communication Enhancement (LACE) program. Journal of the American Academy of Audiology, 17(8), 538-558.

Sweetow, R. W. \& Sabes, J. H. (2010). Auditory training and challenges associated with participation and compliance. Journal of the American Academy of Audiology, 21(9), 586-593.

Yeo, S., Bahng, J., \& Lee, J. H. (2014). Efficacy of auditory training using sentences in noise for hearing aid users. Audiology and Speech Research, 10(1), 65-75. 


\section{APPENDIX}

\section{Summary of Auditory Training and Subject's Response}

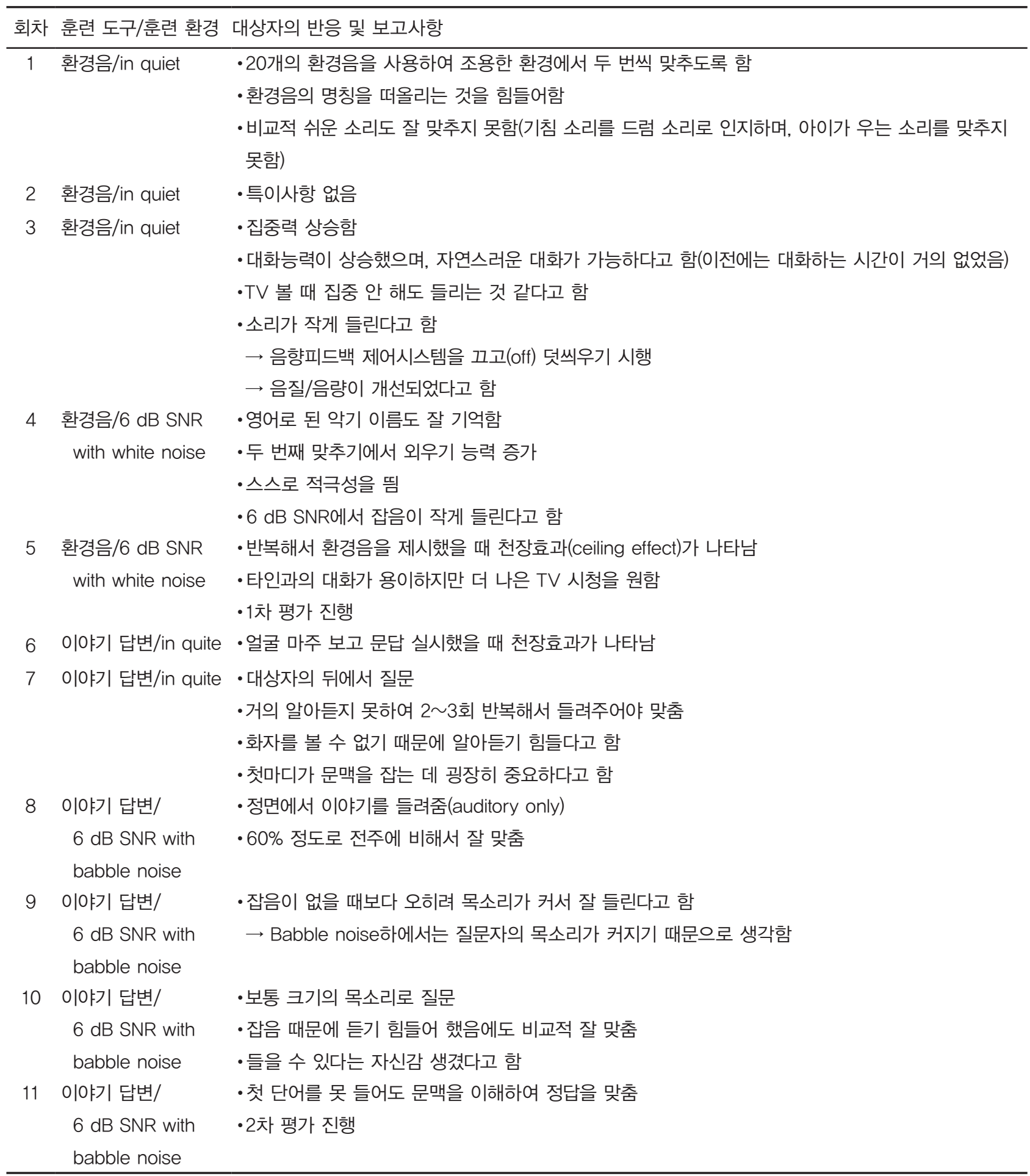

